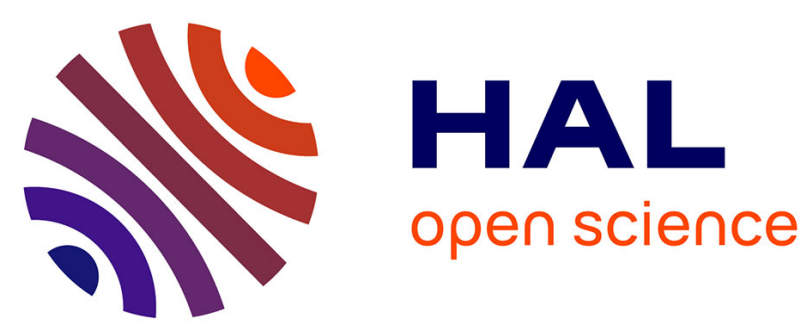

\title{
Synthesis and Characterization of Temperature-Responsive N-Cyanomethylacrylamide-Containing Diblock Copolymer Assemblies in Water
}

Nicolas Audureau, Fanny Coumes, Clémence Veith, Clement Guibert, Jean-Michel Guigner, François Stoffelbach, Jutta Rieger

\section{To cite this version:}

Nicolas Audureau, Fanny Coumes, Clémence Veith, Clement Guibert, Jean-Michel Guigner, et al.. Synthesis and Characterization of Temperature-Responsive N-Cyanomethylacrylamide-Containing Diblock Copolymer Assemblies in Water. Polymers, 2021, 13 (24), pp.4424. 10.3390/polym13244424 . hal-03510495

\section{HAL Id: hal-03510495 \\ https://hal.sorbonne-universite.fr/hal-03510495}

Submitted on 4 Jan 2022

HAL is a multi-disciplinary open access archive for the deposit and dissemination of scientific research documents, whether they are published or not. The documents may come from teaching and research institutions in France or abroad, or from public or private research centers.
L'archive ouverte pluridisciplinaire HAL, est destinée au dépôt et à la diffusion de documents scientifiques de niveau recherche, publiés ou non, émanant des établissements d'enseignement et de recherche français ou étrangers, des laboratoires publics ou privés. 


\title{
Synthesis and Characterization of Temperature-Responsive $N$-Cyanomethylacrylamide-Containing Diblock Copolymer Assemblies in Water
}

\author{
Nicolas Audureau ${ }^{1}$, Fanny Coumes ${ }^{1}\left(\mathbb{D}\right.$, Clémence Veith $^{1}{ }^{(\mathbb{D}}$, Clément Guibert $^{2} \mathbb{D}$, Jean-Michel Guigner ${ }^{3}$, \\ François Stoffelbach $1, * \mathbb{D}$ and Jutta Rieger $1, * \mathbb{D}$
}

1 Polymer Chemistry Team, Institut Parisien de Chimie Moléculaire (IPCM), Sorbonne Université \& CNRS, UMR 8232, 4 Place Jussieu, CEDEX 05, 75252 Paris, France; nicolas.audureau@sorbonne-universite.fr (N.A.); fanny.coumes@sorbonne-universite.fr (F.C.); clemence.veith@hotmail.fr (C.V.)

2 Laboratoire de Réactivité de Surface (LRS), Sorbonne Université, CNRS, 4 Place Jussieu, CEDEX 05, 75252 Paris, France; clement.guibert@sorbonne-universite.fr

3 Institut de Minéralogie, de Physique des Matériaux et de Cosmochimie (IMPMC)-IRD-MNHN, Sorbonne Université \& CNRS, UMR 7590, CEDEX 05, 75252 Paris, France; jean-michel.guigner@sorbonne-universite.fr

* Correspondence: francois.stoffelbach@sorbonne-universite.fr (F.S.); jutta.rieger@sorbonne-universite.fr (J.R.)

Citation: Audureau, N.; Coumes, F.; Veith, C.; Guibert, C.; Guigner, J.-M.; Stoffelbach, F.; Rieger, J. Synthesis and Characterization of

Temperature-Responsive

$\mathrm{N}$-Cyanomethylacrylamide-

Containing Diblock Copolymer Assemblies in Water. Polymers 2021, 13, 4424. https://doi.org/10.3390/ polym13244424

Academic Editors: Khalid Ferji and Jean-Luc Six

Received: 26 November 2021 Accepted: 13 December 2021 Published: 16 December 2021

Publisher's Note: MDPI stays neutral with regard to jurisdictional claims in published maps and institutional affiliations.

Copyright: (c) 2021 by the authors Licensee MDPI, Basel, Switzerland. This article is an open access article distributed under the terms and conditions of the Creative Commons Attribution (CC BY) license (https:// creativecommons.org/licenses/by/ $4.0 /)$
Abstract: We have previously demonstrated that poly(N-cyanomethylacrylamide) (PCMAm) exhibits a typical upper-critical solution temperature (UCST)-type transition, as long as the molar mass of the polymer is limited, which was made possible through the use of reversible additionfragmentation chain transfer (RAFT) radical polymerization. In this research article, we use for the first time $\mathrm{N}$-cyanomethylacrylamide (CMAm) in a typical aqueous dispersion polymerization conducted in the presence of poly( $N, N$-dimethylacrylamide) (PDMAm) macroRAFT agents. After assessing that well-defined PDMAm- $b$-PCMAm diblock copolymers were formed through this aqueous synthesis pathway, we characterized in depth the colloidal stability, morphology and temperatureresponsiveness of the dispersions, notably using cryo-transmission electron microscopy (cryo-TEM), dynamic light scattering (DLS), small angle X-ray scattering (SAXS) and turbidimetry. The combined analyses revealed that stable nanometric spheres, worms and vesicles could be prepared when the PDMAm block was sufficiently long. Concerning the thermoresponsiveness, only diblocks with a PCMAm block of a low degree of polymerization $\left(D P_{n, P C M A m}<100\right)$ exhibited a UCST-type dissolution upon heating at low concentration. In contrast, for higher $D P_{n, P C M A m}$, the diblock copolymer nano-objects did not disassemble. At sufficiently high temperatures, they rather exhibited a temperature-induced secondary aggregation of primary particles. In summary, we demonstrated that various morphologies of nano-objects could be obtained via a typical polymerization-induced self-assembly (PISA) process using PCMAm as the hydrophobic block. We believe that the development of this aqueous synthesis pathway of novel PCMAm-based thermoresponsive polymers will pave the way towards various applications, notably as thermoresponsive coatings and in the biomedical field.

Keywords: polymerization-induced self-assembly; RAFT polymerization; self-assembly; amphiphilic block copolymers; micelles; worms; vesicles; UCST; turbidimetry; synchrotron SAXS

\section{Introduction}

Thermoresponsive polymers presenting an upper or a lower critical solution temperature (UCST or LCST, respectively) in water have been widely investigated, in particular for the development of biomaterials [1-6]. Over the past decade, the study of novel neutral UCST polymers, mainly based on (meth)acrylamide (co)polymers [7-11], broadened the library of available materials. Since 2012, the UCST-behavior of poly(acrylamideco-acrylonitrile) (P(Am-co-AN)) [7], a neutral statistical copolymer of acrylamide and acrylonitrile, has been revealed and since then it has been largely studied for numerous 
applications [12-16]. While it had been generally synthesized by free radical polymerization in DMSO solution, Ferji et al. [17] and some of us [18] demonstrated recently that well defined $\mathrm{P}(\mathrm{Am}-\mathrm{co}-\mathrm{AN})$ copolymers can be synthesized directly in water, using the reversible addition-fragmentation chain transfer (RAFT) radical polymerization. Furthermore, we demonstrated that it was possible to synthesize in situ $\mathrm{P}(\mathrm{Am}-\mathrm{co}-\mathrm{AN})$ based block copolymer nanoparticles using the polymerization-induced self-assembly (PISA) process in water [18] Thermoresponsive spherical particles and short worms, but surprisingly no vesicles could be prepared. In addition, the use of $\mathrm{AN}$ as a comonomer is challenging because it is highly volatile and it has a different reactivity compared to acrylamides $[18,19]$. In addition to technical and reproducibility issues, the monomer distribution in the polymer chains strongly depends on the polymerization method. Looking for a more robust and simple system, we have recently developed a novel UCST polymer platform. We demonstrated that neutral poly(N-cyanomethylacrylamide) (PCMAm), possessing the same function groups as $\mathrm{P}(\mathrm{Am}-\mathrm{co}-\mathrm{AN})$ but merged in a single monomer unit, exhibit a sharp and reversible UCST-type transition in water. The cloud point $\left(\mathrm{T}_{\mathrm{CP}}\right)$ depended on the number-average degree of polymerization $\left(D P_{n}\right)$ and ranged between $54{ }^{\circ} \mathrm{C}$ and $90{ }^{\circ} \mathrm{C}$ [11]. In this study, we wanted to exploit this new UCST platform as a building block to synthesize amphiphilic diblock copolymers assemblies that are possibly thermoresponsive. For that purpose, we used PISA mediated by RAFT in the presence of a neutral poly $(N, N$-dimethylacrylamide) macroRAFT agent used as a hydrophilic stabilizer. The individual block lengths, i.e., $D P_{n} \mathrm{~s}$, of the PDMAm and PCMAm blocks were varied systematically to investigate how they influence the colloidal stability of the nanoparticles and the type of morphology obtained. As the second block is thermoresponsive, we also investigated the impact of temperature variation by means of cryo-transmission electron microscopy (cryo-TEM), dynamic light scattering (DLS), synchrotron small angle X-ray scattering (SAXS) and turbidimetry.

\section{Materials and Methods}

\subsection{Materials}

$\mathrm{N}$-Cyanomethylacrylamide and ethyl 2-(butylthiocarbonothioylthio)propanoate (CTA-1) were synthesized according to previously described protocols [11]. 2,2'-Azobis(isobutyronitrile) (AIBN, $\geq 98 \%$, Aldrich, France), 2,2'-azobis[2-(2-imidazolin-2-yl)propane]dihydrochloride (VA-044) (Aldrich, 98\%), 1,3,5-trioxane (Aldrich, $\geq 99 \%$ ) and N,N-dimethylformamide (DMF, Normapur, VWR, France) were used as received. N,N-Dimethylacrylamide (DMAm) (Aldrich, $\geq 99 \%$ ) was distilled under reduced pressure before use. Deionized water was used for all aqueous polymerizations.

\subsection{Synthesis of the PDMAm MacroRAFT Agents}

Similar to a previously reported protocol [18], in a typical experiment (M3 in Table S1), $303 \mathrm{mg}$ ( $1.14 \mathrm{mmol})$ RAFT agent (CTA-1), and $10.2 \mathrm{mg}(0.062 \mathrm{mmol})$ of AIBN were dissolved in $22.9 \mathrm{~mL}$ DMF (Scheme S1). For the determination of the monomer consumption by ${ }^{1} \mathrm{H}$ - NMR, $19 \mathrm{mg}(0.21 \mathrm{mmol})$ of trioxane were added as an internal reference. After purging the solution with argon for $30 \mathrm{~min}$ in an ice bath, $5.40 \mathrm{~mL}(52.4 \mathrm{mmol})$ of degassed $\mathrm{N}, \mathrm{N}$-dimethylacrylamide (DMAm) were injected into the flask through an air-tight syringe. Afterwards, the flask was placed in a thermostated oil bath at $70{ }^{\circ} \mathrm{C}$. To determine the monomer conversion, aliquots were periodically taken from the reaction medium and analyzed by ${ }^{1} \mathrm{H}-\mathrm{NMR}$. The polymerization was quenched by exposure to air and cooling in an ice bath. The polymer was purified by precipitation in cold diethyl ether, and dried under reduced pressure at $50^{\circ} \mathrm{C}$. The SEC chromatograms in DMF $\left(+\operatorname{LiBr} 1 \mathrm{~g} \mathrm{~L}^{-1}\right)$ are given in Figure S2.

\subsection{Synthesis of PDMAm-b-PCMAm Diblock Copolymers in Water}

In a typical experiment (Entry 7, Table 1), $53 \mathrm{mg}(0.014 \mathrm{mmol})$ of PDMAm 36 -TTC, $500 \mu \mathrm{L}$ of an initiator solution (15.7 mg of VA-044 (2,2'-azobis[2-(2-imidazolin-2-yl) propane]dihydrochloride) diluted in $5.03 \mathrm{~g}$ of water $(0.005 \mathrm{mmol})$ and $599 \mathrm{mg}(5.45 \mathrm{mmol})$ of CMAm were dissolved 
in $6.20 \mathrm{~g}$ water in a $10 \mathrm{~mL}$ septum-sealed round bottom flask. The mixture was purged with argon for $30 \mathrm{~min}$ in a cold-water bath. The flask was immersed in a thermostated oil bath at $45^{\circ} \mathrm{C}$ for $8 \mathrm{~h}$. Monomer conversion was kinetically followed by taking aliquots from the reaction medium and analyzing them by ${ }^{1} \mathrm{H}$ NMR. The polymerization was quenched by exposure to air and placing the flask into an ice bath.

Table 1. Experimental conditions and results for the aqueous polymerizations of CMAm in the presence of various PDMAm-TTC macroRAFT agents \#.

\begin{tabular}{|c|c|c|c|c|c|c|c|c|}
\hline \multirow[b]{2}{*}{ Sample } & \multirow[b]{2}{*}{$\begin{array}{c}{[\mathrm{CMAm}]_{0} /} \\
{[\mathrm{TTC}]_{0} /[\mathrm{A}]_{0}}\end{array}$} & \multirow{2}{*}{$\begin{array}{l}\text { Time } \\
\text { (h) }\end{array}$} & \multirow{2}{*}{$\begin{array}{c}\text { Conv. } \\
(\%)\end{array}$} & \multirow[b]{2}{*}{$D P_{n, t h}{ }^{c}$} & \multirow{2}{*}{$\begin{array}{c}M_{\mathrm{n}, \mathrm{th}^{\mathrm{c}}} \\
\left(\mathrm{kg} \mathrm{mol}^{-1}\right)\end{array}$} & \multicolumn{2}{|c|}{ SEC DMF } & \multirow[b]{2}{*}{$\begin{array}{l}\text { Visual Aspect } \\
\leq 45{ }^{\circ} \mathrm{C}^{\mathrm{e}}\end{array}$} \\
\hline & & & & & & $\begin{array}{c}M_{\mathrm{n}}^{\mathrm{d}} \\
\left(\mathrm{kg} \mathrm{mol}^{-1}\right)\end{array}$ & $\bigoplus^{\mathrm{d}}$ & \\
\hline \multicolumn{9}{|c|}{ PDMAm-macroRAFT DP $P_{n}=13$} \\
\hline 1 & $100 / 1 / 0.23$ & 2.8 & 87 & 87 & 11.1 & 22.1 & 1.15 & $\begin{array}{l}\text { Turbid, phase separation } \\
\text { during polymerization }\end{array}$ \\
\hline \multicolumn{9}{|c|}{ PDMAm-macroRAFT DP $P_{n}=23$} \\
\hline 2 & $50 / 1 / 0.24$ & 2.8 & 83 & 42 & 7.2 & 12.8 & 1.14 & \multirow{3}{*}{$\begin{array}{c}\text { Transparent } \\
\text { Slightly turbid } \\
\text { Phase separation during } \\
\text { polymerization }\end{array}$} \\
\hline 3 & $100 / 1 / 0.15$ & 6 & 93 & 93 & 12.8 & 24.4 & 1.15 & \\
\hline 4 & $225 / 1 / 0.32$ & 4 & 86 & 194 & 20.8 & 34.9 & 1.54 & \\
\hline \multicolumn{9}{|c|}{ PDMAm-macroRAFT DP $P_{n}=36$} \\
\hline 5 & $100 / 1 / 0.45$ & 8.3 & 91 & 91 & 13.8 & 23.4 & 1.16 & Slightly turbid \\
\hline 6 & $200 / 1 / 0.35$ & 5 & 93 & 186 & 24.3 & 42.4 & 1.23 & Slightly turbid \\
\hline 7 & $400 / 1 / 0.35$ & 8 & 90 & 360 & 43.4 & 83.5 & 1.63 & Milky solution \\
\hline
\end{tabular}

\# Polymerizations performed in water at $45^{\circ} \mathrm{C}$ in presence of PDMAm $\mathrm{x}$-TTC using VA-044 as a radical initiator at targeted solids contents of $10 \mathrm{wt} \%$. ${ }^{a}$ Initial molar ratio of CMAm/ PDMAm-TTC/ VA-044. ${ }^{b}$ Determined by ${ }^{1} \mathrm{H}$ NMR. ${ }^{\mathrm{c}}$ Theoretical number-average degree of polymerization, $D P_{n, t h}$, and theoretical number-average molar mass, $M_{n, t h}$, determined via the monomer conversion. ${ }^{\mathrm{d}}$ Number-average molar mass $M_{\mathrm{n}}$, and dispersity, $\oslash$, determined by SEC in DMF $\left(+\mathrm{LiBr} 1 \mathrm{~g} \mathrm{~L}^{-1}\right)$ with a PMMA calibration. ${ }^{\mathrm{e}}$ Visual observations were done at $45^{\circ} \mathrm{C}$ and $4{ }^{\circ} \mathrm{C}$; no difference was noticed at both temperatures.

\subsection{Characterization Techniques}

\subsubsection{Nuclear Magnetic Resonance Spectroscopy (NMR)}

${ }^{1} \mathrm{H}-\mathrm{NMR}$ spectra were recorded in DMSO-d 6 (unless stated differently) at $300 \mathrm{~K}$ on a Bruker $300 \mathrm{MHz}$ spectrometer in $5 \mathrm{~mm}$ diameter tubes.

\subsubsection{Size Exclusion Chromatography (SEC)}

The SEC measurements were carried out at $60^{\circ} \mathrm{C}$ in DMF $\left(+\mathrm{LiBr}, 1 \mathrm{~g} \mathrm{~L}^{-1}\right)$ as mobile phase at a flow rate of $0.8 \mathrm{~mL} \mathrm{~min}^{-1}$ and with toluene as a flow rate marker. All polymers were prepared at a concentration ranging from 5 to $10 \mathrm{mg} \mathrm{mL}^{-1}$, filtered through a $0.20 \mu \mathrm{m}$ PTFE membrane; $100 \mu \mathrm{L}$ of each solution were injected for each measurement for analysis. The separation system was composed of two PSS GRAM $1000 \AA$ columns $(8 \times 300 \mathrm{~mm}$; separation limits: 1 to $\left.1000 \mathrm{~kg} \mathrm{~mol}^{-1}\right)$ and one PSS GRAM $30 \AA(8 \times 300 \mathrm{~mm}$; separation limits: 0.1 to $10 \mathrm{~kg} \mathrm{~mol}^{-1}$ ) coupled with a modular differential refractive index (RI) detector (Viscotek TDA, Malvern, France). Molar masses $\left(M_{n}\right.$, the number-average molar mass, $M_{\mathrm{w}}$, the weight-average molar mass) and dispersities $\left(\nexists=M_{\mathrm{w}} / M_{\mathrm{n}}\right)$ were calculated using the OmniSEC 5.12 software with a calibration curve based on narrow PMMA standards (from Polymer Standard Services, Mainz, Germany).

\subsubsection{Turbidimetry}

The turbidimetry measurements of copolymers in water were performed on a Cary 100 UV-Vis spectrophotometer (Agilent) equipped with a Peltier-type temperature control system by measuring the transmittance at a wavelength of $670 \mathrm{~nm}$. The heating/cooling rate was maintained constant at $1{ }^{\circ} \mathrm{C} \mathrm{min}-1$. Samples were prepared at a concentration of 
$1 \mathrm{wt} \%$ by diluting the polymer dispersion in ultra-pure water. The cloud point temperature $\left(\mathrm{T}_{\mathrm{CP}}\right)$ was determined at the inflection point.

\subsubsection{Dynamic Light Scattering (DLS)}

The DLS measurements were carried out on a Zetasizer Nano S90 from Malvern (France; $90^{\circ}$ angle, $5 \mathrm{~mW} \mathrm{He}-\mathrm{Ne}$ laser at $633 \mathrm{~nm}$ ) to determine the z-average particle diameter $\left(D_{\mathrm{z}}\right)$ of diluted dispersions in water at $0.1 \mathrm{wt} \%$ (unless stated differently). Polydispersity indices (PDI) were determined using the cumulant method.

\subsubsection{Cryogenic Transmission Electron Microscopy (Cryo-TEM)}

Polymer solutions were prepared at $1 \mathrm{wt} \%$ in ultra-pure water. Typically, $3 \mu \mathrm{L}$ of the solution was deposited on a quantifoil grid. After removing the excess of solution with a Whatman filter paper, the grid was immediately frozen in liquid ethane. The observations were carried out at $-180^{\circ} \mathrm{C}$ with a JEM-2100 LaB 6 microscope (JEOL) operating at $200 \mathrm{kV}$. The images were taken on a Gatan US 1000, $2 \mathrm{k}$ by $2 \mathrm{k}$ CCD camera.

\subsubsection{Small Angle X-ray Scattering Analyses (SAXS)}

Selected samples were analyzed by small angle X-ray scattering (SAXS) measurements on the SWING beamline of the SOLEIL Synchrotron (Saint Aubin, France). The measurements were performed during two series of measurements at an energy of $7 \mathrm{keV}$ $(\lambda=1.77 \AA)$ (respectively at $12 \mathrm{keV}(\lambda=1.03 \AA))$, with an exposure time of $1000 \mathrm{~ms}$ and a gap time of $500 \mathrm{~ms}$ and measured by a two-dimensional CCD detector localized at a distance of $2131 \mathrm{~mm}$ (respectively $3500 \mathrm{~mm}$ ) from the sample. The measurements were performed at different concentrations and different temperatures thanks to a thermostated capillary-holder device. Standard correction procedures were applied for X-ray beam transmission, signal subtraction of the $1.5 \mathrm{~mm}$ capillary filled with the solvent and detector efficiency. The softwares Foxtrot ${ }^{\circledR}$ and SASview ${ }^{\circledR}$ were used to achieve such data reduction. The data was fitted with the SASview ${ }^{\circledR}$ software (http:/ / www.sasview.org/, accessed in 15 May 2021). According to the morphologies observed by cryo-TEM the data were fitted with the form factor of a lognormal distribution of either spheres, cylinders or vesicles. The values obtained are summarized in Table 2 and the fits are displayed in SI, Figure S4.

Table 2. Dimensions of the cylindrical micelles deduced from DLS measurements, cryo-TEM analyses and the fit of SAXS data.

\begin{tabular}{|c|c|c|c|c|c|c|c|c|}
\hline $\begin{array}{l}\text { Sample } \\
\text { Name }\end{array}$ & $\begin{array}{c}D P_{n} \\
\text { PCMAm }\end{array}$ & Morphology & $\begin{array}{c}D_{\mathrm{z}}^{\mathrm{a}} \\
\text { DLS } \\
@ 25^{\circ} \mathrm{C} \\
\text { (PDI) }^{\mathrm{b}}\end{array}$ & $\begin{array}{c}D_{\mathrm{n}} \mathrm{c} \\
\text { Cryo-TEM } \\
@ \mathrm{RT} \\
(\sigma)^{\mathrm{d}}\end{array}$ & $\begin{array}{c}D_{\mathrm{n}}{ }^{\mathrm{c}} \\
\text { Cryo-TEM } \\
@ 70^{\circ} \mathrm{C} \\
(\sigma)^{\mathrm{d}}\end{array}$ & $\begin{array}{c}D^{\mathrm{e}} \\
\text { SAXS } \\
@ 25^{\circ} \mathrm{C} \\
\left(\sigma^{\prime}\right)^{\mathrm{f}}\end{array}$ & $\begin{array}{c}\text { Vesicle } \\
\text { Membrane } \\
\text { Thickness } \\
\text { Cryo-TEM } \\
\text { @RT } \\
(\sigma)^{d}\end{array}$ & $\begin{array}{c}\text { Vesicle } \\
\text { Membrane } \\
\text { Thickness } \\
\text { SAXS @ } 25 \\
{ }^{\circ} \mathrm{C} \\
\left(\sigma^{\prime}\right)^{\mathrm{f}}\end{array}$ \\
\hline 5 & 91 & Sphere & $\begin{array}{l}29 \mathrm{~nm} \\
(0.23)\end{array}$ & $\begin{array}{c}14 \mathrm{~nm} \\
(1.9 \mathrm{~nm})\end{array}$ & $\begin{array}{c}15 \mathrm{~nm} \\
(1.2 \mathrm{~nm})\end{array}$ & $\begin{array}{l}18 \mathrm{~nm} \\
(0.15)\end{array}$ & - & - \\
\hline 6 & 186 & Worm & $\begin{array}{c}153 \mathrm{~nm} \text { * } \\
(0.23)\end{array}$ & $\begin{array}{c}21 \mathrm{~nm} \\
(2.4 \mathrm{~nm})\end{array}$ & $\begin{array}{c}19 \mathrm{~nm} \\
(1.5 \mathrm{~nm})\end{array}$ & $\begin{array}{c}22 \mathrm{~nm} \\
(0.10) \\
{[>300 \mathrm{~nm}]^{\mathrm{g}}}\end{array}$ & - & - \\
\hline 7 & 360 & Vesicle & $\begin{array}{c}551 \mathrm{~nm} \\
(0.16)\end{array}$ & $\begin{array}{c}592 \mathrm{~nm} \\
(192 \mathrm{~nm})\end{array}$ & $\begin{array}{c}391 \mathrm{~nm} \\
(110 \mathrm{~nm})\end{array}$ & $>300 \mathrm{~nm} \mathrm{~g}^{\mathrm{g}}$ & $\begin{array}{c}22 \mathrm{~nm} \\
(2.5 \mathrm{~nm})\end{array}$ & $\begin{array}{c}26 \mathrm{~nm} \\
(0.1)\end{array}$ \\
\hline
\end{tabular}

${ }^{a}$ DLS realized at $0.1 \mathrm{wt} \%$ in water (see Figure S3). ${ }^{\mathrm{b}}$ Polydispersity index determined with a cumulant method. ${ }^{\mathrm{c}} D_{\mathrm{n}}=$ number-average diameter determined on 20 representative nano-objects by cryo-TEM at $1 \mathrm{wt} \%$ in water. ${ }^{\mathrm{d}}$ Standard deviation. ${ }^{\mathrm{e}} \mathrm{D}=$ median diameter determined by SAXS measurements realized at $1 \mathrm{wt} \%$ in water, modelled by form factors of objects displaying lognormal distributions of dimensions (see Figure S4). ${ }^{\mathrm{f}}$ Polydispersity determined with a lognormal distribution. ${ }^{\mathrm{g}}$ Length of the worms or vesicle size cannot be determined by SAXS since it exceeds the analysis window. * Sphere-equivalent diameter. 


\section{Results and Discussion}

3.1. Synthesis of PDMAm-b-PCMAm Diblock Copolymer Assemblies by RAFT-Mediated Aqueous Dispersion Polymerization

In order to produce PDMAm- $b$-PCMAm diblock copolymers self-assemblies in water, our synthetic approach relies on a PISA strategy, where CMAm is polymerized in water in the presence of hydrophilic PDMAm-TTC macroRAFT agents (Scheme 1) in conditions where self-assembly occurs during polymerization. In our previous study [11], UCST-type cloud points $\left(\mathrm{T}_{\mathrm{CP}}\right.$ ) between $54{ }^{\circ} \mathrm{C}$ and over $90^{\circ} \mathrm{C}$ were determined (at $0.5 \mathrm{wt} \%$ ) for PCMAm homopolymers depending on the number-average degree of polymerization $\left(D P_{n}\right.$ between 20 and 180). Recent experiments revealed that the UCST behavior, formerly mostly studied at $0.5 \mathrm{wt} \%$, was also preserved at $10 \mathrm{wt} \%$, which is actually close to the concentration at which PISA can be reached; for instance, for a PCMAm homopolymer with $D P_{\mathrm{n}}=113$, we determined visually a $\mathrm{T}_{\mathrm{cp}}$ above $60^{\circ} \mathrm{C}$.

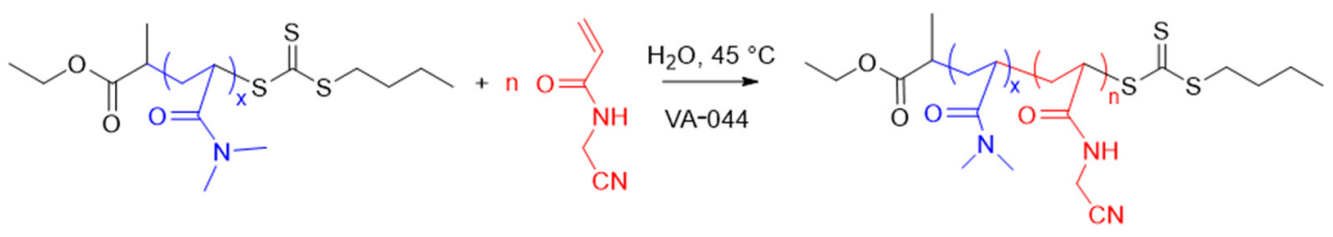

Scheme 1. Synthesis route for the preparation of PDMAm- $b$-PCMAm diblock copolymers in water.

Therefore, the polymerization temperature was set to $45^{\circ} \mathrm{C}$, which is a priori significantly below the $\mathrm{T}_{\mathrm{CP}}$ determined for the PCMAm homopolymers, while the CMAm monomer is soluble. These polymerization conditions should therefore lead to the in situ formation of nano-assemblies composed of diblock copolymers, as expected for a typical PISA process proceeding through an aqueous dispersion polymerization mechanism. 2,2'-Azobis[2-(2-imidazolin-2-yl)propane]dihydrochloride (VA-044) was chosen as watersoluble radical initiator for its low decomposition temperature (10 h half-life dissociation temperature in water $=44^{\circ} \mathrm{C}$ ) [20].

In three series of experiments, we systematically varied the length of the PDMAm-TTC macroRAFT agents and the PCMAm block. Therefore, three PDMAm-TTC macroRAFT agents with $D P_{\mathrm{n}}=13,23$ and 36, respectively, were synthesized according to a reported procedure [18] and well-defined polymers with molar mass dispersities $Đ$ below 1.2 were obtained (see Table S1 and Figure S2). For the synthesis of the PDMAm- $b$-PCMAm diblock copolymers, the length of the PCMAm block was tuned by the initial monomer to PDMAmTTC molar ratio. The polymerization conditions and results are summarized in Table 1. Generally, in all experiments high monomer conversions were reached.

Size exclusion chromatography (SEC) indicated the quantitative extension of PDMAmTTC to PDMAm- $b$-PCMAm diblock copolymers with a complete shift of the PDMAm macroRAFT agent signal (Figure 1). Dispersities were excellent $(\boxplus \leq 1.2)$, except for sample $4\left(\mathrm{PDMAm}_{23}-\mathrm{b}-\mathrm{PCMAm}{ }_{194}\right)$ and in particular sample $7\left(\mathrm{PDMAm}_{36}-b-\mathrm{PCMAm}_{360}\right)$, for which a shoulder at the higher molar mass side - generally attributed to the formation of dead chains by chain recombination - was observed. 
(A)

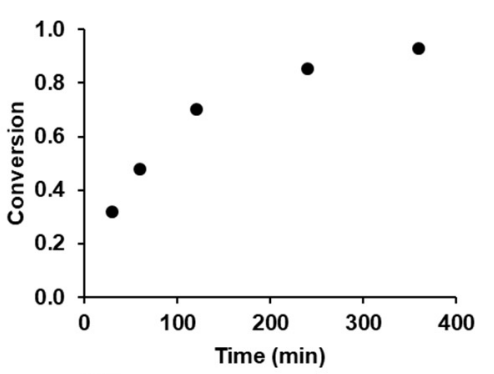

(C)

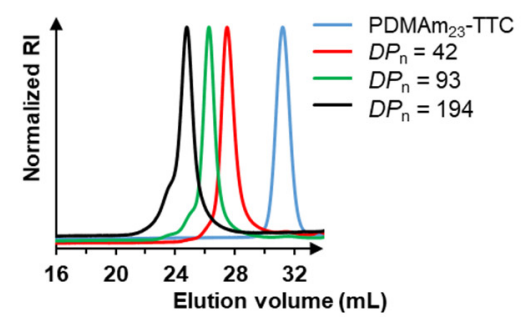

(B)

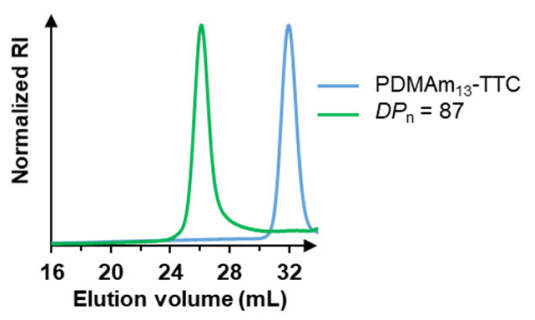

(D)

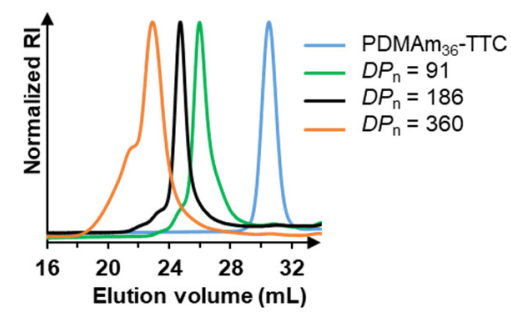

Figure 1. (A) Monomer conversion monitored by ${ }^{1} \mathrm{H}$ NMR in DMSO- $\mathrm{d}_{6}$ for $\mathrm{PDMAm}_{23}-b-\mathrm{PCMAm}_{93}$ (Entry 3, Table 1); Normalized size exclusion chromatograms of PDMAm macroRAFT agents and the resulting diblock copolymers using PDMAm macroRAFT agents of various $D P_{\mathrm{n}}:(\mathbf{B}) D P_{\mathrm{n}}=13 ;(\mathbf{C}) D P_{\mathrm{n}}=23$; (D) $D P_{\mathrm{n}}=36$. The $D P_{\mathrm{n}}$ reported in the figures is the $D P_{\mathrm{n}}$ of the PCMAm block determined via the monomer conversion.

\subsection{Impact of $D P_{n}$ of PDMAm and PCMAm on Colloidal Stability and Morphology}

Macroscopically, important differences were observed for the three series of experiments, prepared with the three different macroRAFT agents (Table 1). Using the shortest macroRAFT agent $\left(D P_{n}=13\right)$, the reaction medium phase separated during polymerization even though a relatively short PCMAm block was targeted $\left(D P_{0}=[C M A m]_{0} /[T T C]_{0}=100\right)$. In line with the literature [21,22], this observation should be explained by an insufficient stabilization due to a too short stabilizer. Indeed, a stable dispersion was obtained when the experiment was repeated with the two longer macroRAFT agents, with $D P_{n}=23$ and 36 , samples 3 and 5. When the length of the solvophobic PCMAm block was increased to $D P_{0} \sim 200$, we observed again a macroscopic phase separation for sample 4 prepared with the macroRAFT agent of $D P_{\mathrm{n}}=23$. Again, increasing the length of the stabilizer led to a stable dispersion, sample 6. It can thus be concluded that the longest PDMAm stabilizer with $D P_{\mathrm{n}}=36$ is the most suitable one to polymerize CMAm in water leading to the formation of stable dispersions over a large molar mass range of the PCMAm block.

In order to determine the size and morphology of the colloids, the dispersions were analyzed by cryo-TEM as shown in Figure 2 (top, deposition at room temperature). For sample 5 with the shortest PCMAm block, tiny spheres with an average diameter of $14 \mathrm{~nm}$ were observed. In classical PISA, higher order morphologies can be obtained by progressively increasing the solvophobic block length-provided that chain reorganization is possible. Indeed, for the intermediate PCMAm block length $\left(D P_{\mathrm{n}}=186\right)$, nanoworms with an average diameter of $21 \mathrm{~nm}$ were observed. Furthermore, this sample exhibited an increased viscosity, which is commonly observed for worm dispersions [23-25]. For the longest PCMAm block $\left(D P_{\mathrm{n}}=360\right)$, large vesicles-with a membrane thickness of $22 \mathrm{~nm}$ - were clearly observed. The diameter of the nanospheres and worms, and the membrane thickness of the vesicles increased thus with increasing $D P_{\mathrm{n}}$ of PCMAm, as expected. 

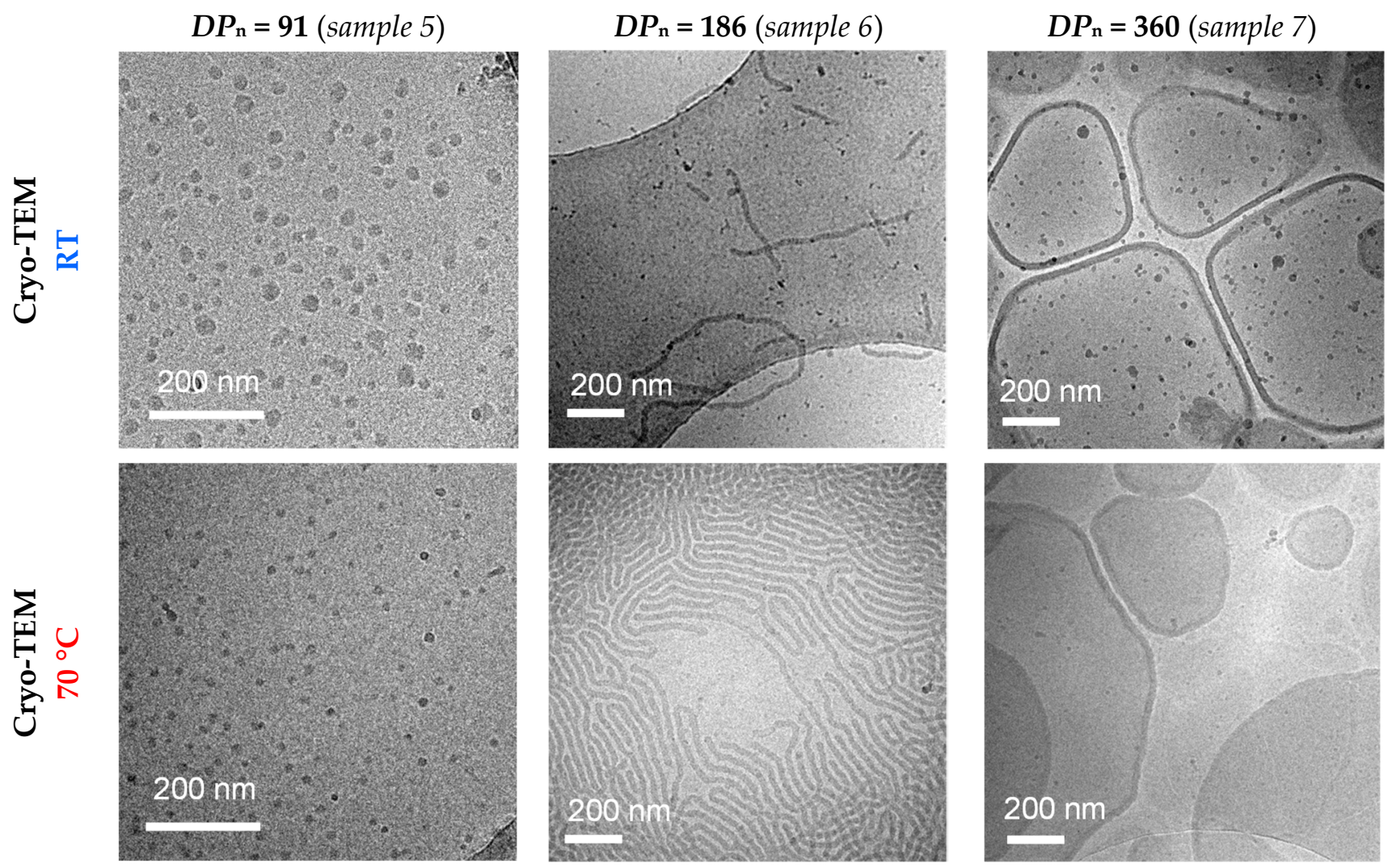

Figure 2. Representative cryo-TEM images of $\mathrm{PDMAm}_{36}-\mathrm{b}-\mathrm{PCMAm} \mathrm{m}_{x}$ dispersions, prepared at room temperature or at $70{ }^{\circ} \mathrm{C}$. Sample concentration $=1 \mathrm{wt} \%$ in water (except for $D P_{\mathrm{n}}=186$, prepared at $\mathrm{RT}$ at $<0.1 \mathrm{wt} \%$ and at $70{ }^{\circ} \mathrm{C}$ at $0.1 \mathrm{wt} \%$ ).

In order to confirm these results, SAXS and DLS measurements were also performed at $25^{\circ} \mathrm{C}$ (Figure 3 and Figure S3, respectively) and the results are summarized in Table 2. The SAXS measurements performed at $1 \mathrm{wt} \%$ in water confirmed the sphere, worm and vesicle shapes (see fits Figure S4). Their modelled diameters and the thickness of the vesicle membrane were in good agreement with those determined by cryo-TEM (Table 2).

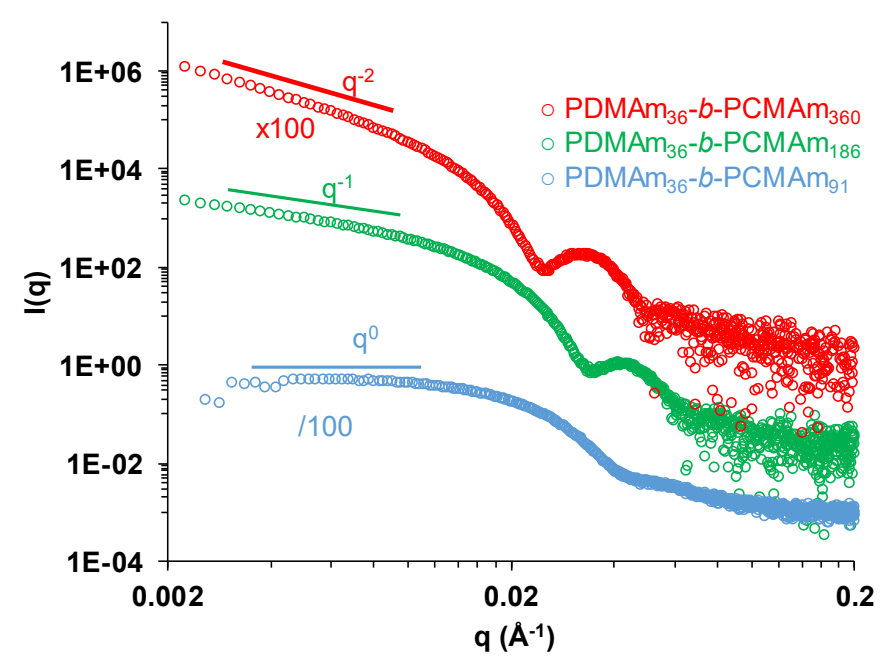

Figure 3. SAXS intensity $\left(\mathrm{I}(\mathrm{q})\right.$ ) versus scattering vector $(\mathrm{q})$ for PDMAm $_{36}$-b-PCMAm ${ }_{\mathrm{x}}$ (samples 5, 6 and 7) in water at $1 \mathrm{wt} \%$ at $25^{\circ} \mathrm{C}$.

The DLS measurements (Table 2) further confirmed the diameter of the vesicles. Concerning the spherical nano-objects, the size determined by DLS was significantly higher 
than the one determined by cryo-TEM. This difference might in part be explained by the absence of contrast of hydrated chains in cryo-TEM. Therefore, we may assume that the diameters determined by cryo-TEM comprises only the dehydrated core of the aggregate while DLS determined a hydrodynamic diameter of the whole object.

\subsection{Thermoresponsive Behavior}

We have previously demonstrated that PCMAm chains possess a UCST-type solubility behavior in water. We therefore investigated whether the PDMAm- $b$-PCMAm diblock copolymer assemblies obtained directly in water showed any temperature-induced transitions.

First, the series prepared with the longest stabilizer (PDMAm 36 -TTC, Samples 5, 6 and 7) was analyzed by temperature-dependent turbidimetry measurements at $1 \mathrm{wt} \%$ in water. Figure 4 does not show any significant temperature dependency for Samples 5 and 7 (spheres and vesicles). In contrast, a clear decrease in transmittance upon heating was observed for the worm sample (Sample 6). The temperature-induced change in transmittance was reversible but presented a large hysteresis.

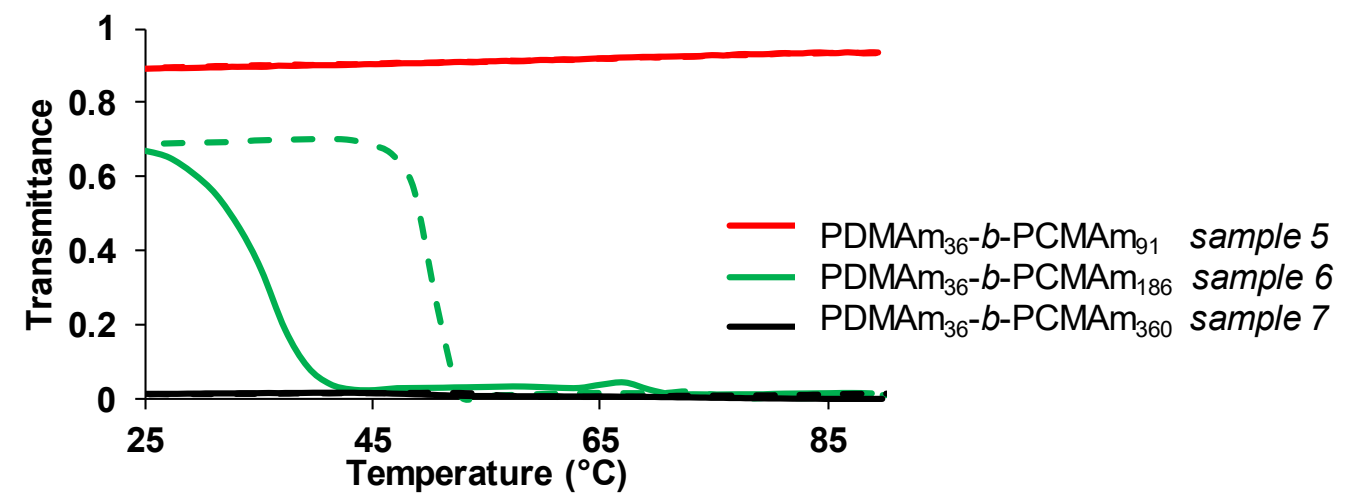

Figure 4. Turbidity curves of PDMAm- $b$-PCMAm dispersions prepared at $1 \mathrm{wt} \%$ in water $(\lambda=670 \mathrm{~nm}$, $1{ }^{\circ} \mathrm{C} \min ^{-1}$ ) (Table 1). First cooling: solid lines; second heating: dashed lines.

In order to better understand the influence of temperature on these samples, heated samples were also characterized by cryo-TEM, DLS and SAXS. For the cryo-TEM experiments, the samples were heated to $70^{\circ} \mathrm{C}$ before rapid deposition on the cryo-TEM grids. The results are illustrated in Figure 2 (bottom). For Samples 5 and 6 (spheres and worms), the comparison of samples deposited at $70{ }^{\circ} \mathrm{C}$ and room temperature Figure 2 (bottom and top) indicated that the heating did not induce any significant change in morphology nor in size (Table 2). The observed change in turbidity for the worm Sample 6 should thus not be related to a change in morphology. It might rather be explained by a secondary aggregation of the initial worms, leading to an increase in turbidity through the formation of large scattering objects. Such secondary aggregation, which should be triggered by a diminished colloidal stability at higher temperature, might even end-up with the partial precipitation of the sample, as already observed in the literature for a similar system [18]. Actually, SAXS measurements performed on Sample 6 (worms) at $1 \mathrm{wt} \%$ at $70{ }^{\circ} \mathrm{C}$ (Figure S5A) confirmed that the system becomes colloidally unstable upon heating since the diffractogram of the resulting sample was similar to that of pure water. Indeed, in contrast to turbidity measurements, SAXS analyses were actually performed without stirring. Thus, the absence of signal in scattering intensity must be attributed to polymer precipitation to the capillary bottom that occurs over time when the sample is not stirred. Interestingly, SAXS analyses performed at $70^{\circ} \mathrm{C}$ at lower concentration $(0.5 \mathrm{wt} \%$ and $0.1 \mathrm{wt} \%$, Figure S5B,C) did not induce precipitation of the sample (since a scattering signal could be observed at $70{ }^{\circ} \mathrm{C}$ ). Furthermore, these experiments showed that the process was fully reversible as the diffractogram recorded at $20{ }^{\circ} \mathrm{C}$ (after cooling back to $20{ }^{\circ} \mathrm{C}$ ) perfectly overlayed the initial one. 
Concerning Sample 7 (vesicles), in agreement with the turbidity measurements, the DLS measurements of Sample 7 (Figure S3C) indicated the presence of large aggregates at both 25 and $65{ }^{\circ} \mathrm{C}$, with no significant temperature-dependency. Cryo-TEM analyses of the sample deposited at $70{ }^{\circ} \mathrm{C}$ (Figure 2, bottom) suggested that the heating process might however have changed the structure of the vesicles' membrane. Whereas clearly defined at RT (Figure 2, top), on selected images the membrane seems altered and partially disaggregated at $70{ }^{\circ} \mathrm{C}$ (Figure S6). However, on most regions of the grid, pristine vesicles were observed (Figure 2, bottom), which makes it difficult to conclude whether heating has truly an impact on the vesicle membrane or not. SAXS analyses at $1 \mathrm{wt} \%$, performed successively at $25^{\circ} \mathrm{C}, 70^{\circ} \mathrm{C}$ and cooled back at $25^{\circ} \mathrm{C}$ (Figure 5), supported our assumption that the sample might evolve with temperature. Indeed, a clear change in the scattering profile was observed, when the pristine sample analyzed at $25{ }^{\circ} \mathrm{C}$ was heated to $70{ }^{\circ} \mathrm{C}$. In contrast to sample 6 , visually, no macroscopic precipitation was observed. The clear evolution of the diffractogram with temperature seemed rather to correspond to the appearance of a structure factor characteristic for interactions between vesicles. At this stage, we assume that this change in the scattering profile could be attributed to an increase of attractions between vesicles potentially leading to the formation of secondary aggregates when the sample is heated. Indeed, the peak observed at $70{ }^{\circ} \mathrm{C}$ on the scattering intensity profile corresponds to a characteristic distance between interacting. This peak allowed us to calculate a characteristic distance $d$ of $35.0 \mathrm{~nm}(d=2 \pi / q)$ between objects. Interestingly, after cooling the sample back to room temperature, the scattering profile became closer to the initial one, indicating that the temperature-induced changes are at least partially reversible on the timescale of the experiment. These vesicles seem still partially aggregated, but the distance between them increased as evidenced by the characteristic peak, displaying an inter-vesicle distance of $52.3 \mathrm{~nm}$. Interestingly, SAXS measurements performed at lower concentration, namely $0.5 \mathrm{wt} \%$ and $0.1 \mathrm{wt} \%$ (Figure S7), showed that the aggregation process-still visible at $70{ }^{\circ} \mathrm{C}$-was totally reversible at these lower concentrations.

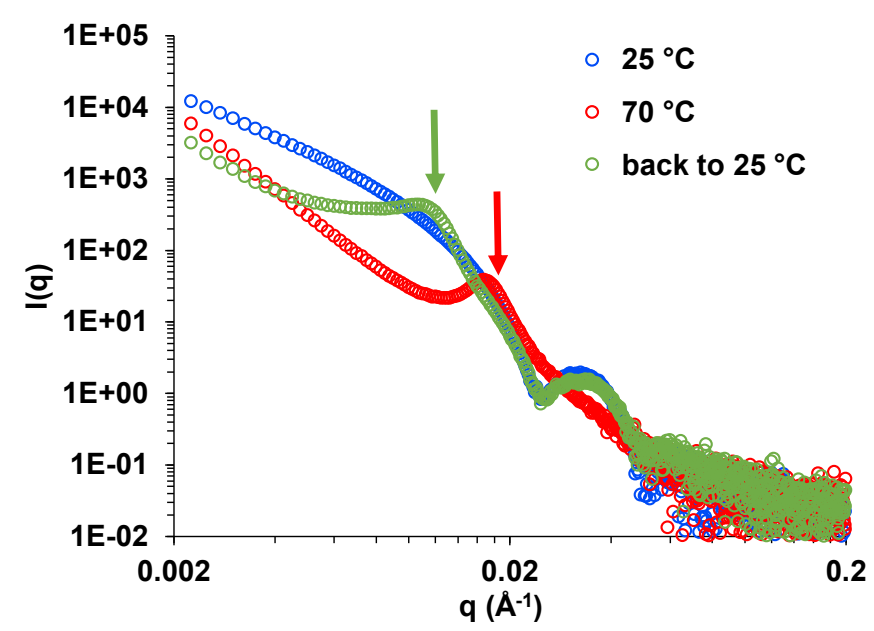

Figure 5. SAXS intensity (I(q)) versus scattering vector (q) for PDMAm $_{36}-b$-PCMAm 360 (Sample 7) in water at $1 \mathrm{wt} \%$, at $25{ }^{\circ} \mathrm{C}$ (in blue), $70{ }^{\circ} \mathrm{C}$ (in red) and back to $25^{\circ} \mathrm{C}$ (in green). The arrows designate $d$, the reciprocal length corresponding to the inter-vesicle distance.

These combined analyses let us conclude that-upon heating-the worms (sample 6) aggregate into larger, secondary aggregates that precipitate with time, while the vesicles (Sample 7) remained colloidally dispersed even at high temperature, at least at the time scale of the experiment.

Concerning the spheres (Sample 5), turbidity, cryo-TEM and DLS (Figure S8C) performed at $1 \mathrm{wt} \%$ suggested that they were not sensitive to modification in temperature. However, we cannot exclude an impact of concentration on the stability, reorganization or destabilization of the nano-objects with temperature. Actually, whereas the DLS analyses 
of the spheres (Sample 5) clearly did not reveal any temperature-induced transition (at least up to $65^{\circ} \mathrm{C}$ ) at $1 \mathrm{wt} \%$ in water (Figure S8C), DLS at $0.1 \mathrm{wt} \%$ (Figure S3A) indicated a typical UCST-type dissociation of the aggregates upon heating: at $65^{\circ} \mathrm{C}$ the count rate was significantly decreased and no precipitation was observed. SAXS analyses at $0.1 \mathrm{wt} \%$ (Figure S9) confirmed this conclusion. The results highlight the crucial importance of the polymer concentration on the UCST transition as already observed for certain thermoresponsive polymers $[18,26]$. In contrast, for the worms and vesicles, decreasing the concentration from 1 to $0.1 \mathrm{wt} \%$ (DLS: Figure S3; SAXS: Figure S5B, S5C and S7) did not lead to the dissociation of the assemblies. The absence of a UCST-type behavior is certainly related to the longer PCMAm block, which should increase the transition temperature above $90^{\circ} \mathrm{C}[11]$.

In order to study the impact of the PDMAm-stabilizer length on the temperaturesensitivity, in a second series of experiments, we also screened the temperature-dependent turbidity for Samples 1 and 3 (PDMAm $_{13}-b$-PCMAm 87 and PDMAm $_{23}-b$-PCMAm 93 respectively), which possess a similar, relatively short PCMAm block $\left(D P_{\mathrm{n}} \sim 90\right)$, but considerably shorter stabilizers than Sample 5 (PDMAm $_{36}-b$-PCMAm $\left.{ }_{91}\right)$. The results are summarized in Figure 6.

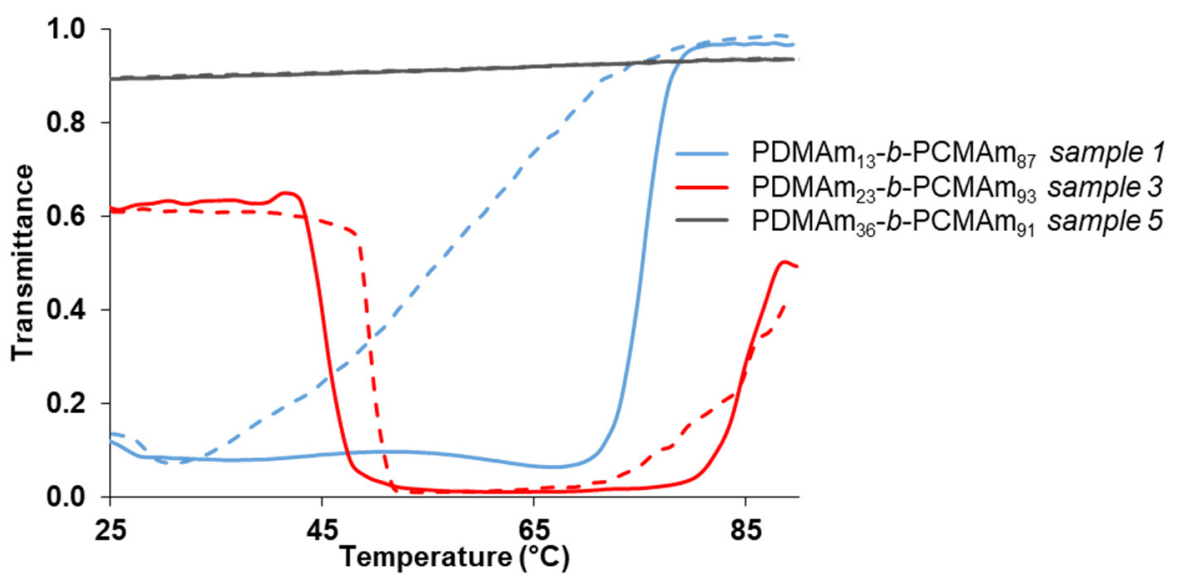

Figure 6. Turbidity curves of PDMAm $_{x}-b$-PCMAm $\sim 90$ dispersions (Table 1 ) prepared at $1 \mathrm{wt} \%$ in water $\left(\lambda=670 \mathrm{~nm}, 1^{\circ} \mathrm{C} \mathrm{m^{-1 }}\right)$. First cooling: solid lines; second heating: dashed lines.

We should remind here, that Sample 1 (PDMAm $13-b-\mathrm{PCMAm}_{87}$ ) was colloidally unstable and phase-separated during polymerization and during storage at $4{ }^{\circ} \mathrm{C}$ at $10 \mathrm{wt} \%$. Turbidity measurements at $1 \mathrm{wt} \%$ (Figure 6) combined with DLS at $1 \mathrm{wt} \%$ (Figure S8A) revealed a UCST-type transition with a cloud point $\left(\mathrm{T}_{\mathrm{CP}}\right)$ about $76{ }^{\circ} \mathrm{C}\left(1^{\text {st }}\right.$ cooling). The DLS measurements at temperatures $90{ }^{\circ} \mathrm{C}$ at $1 \mathrm{wt} \%$ showed a very low scattering intensity close to the one of water, supposing the complete dissolution of the polymer chains, as expected for a UCST-type polymer and observed for the PCMAm homopolymer. The determined $\mathrm{T}_{\mathrm{CP}}$ is actually slightly lower that the $\mathrm{T}_{\mathrm{CP}}$ determined for a PCMAm homopolymer of similar molar mass $\left(D P_{\mathrm{n}}=73: \mathrm{T}_{\mathrm{CP}}(0.5 \mathrm{wt} \%)=85^{\circ} \mathrm{C}\right)$ [11]. This observation is in agreement with the literature, where it has been reported that the presence of a hydrophilic polymer block increases the overall solubility of the copolymer thus lowering the $\mathrm{T}_{\mathrm{CP}}$ [18].

For Sample 3 ( $\left.\mathrm{PDMAm}_{23}-b-\mathrm{PCMAm}_{93}\right)$, the turbidimetry measurements-performed under stirring at $1 \mathrm{wt} \%$-showed a more complex temperature transition, with a decrease in transmittance above $40{ }^{\circ} \mathrm{C}$ followed by an increase in transmittance above $80^{\circ} \mathrm{C}$, which was not caused by a macroscopic precipitation of the sample. At room temperature, macroscopically, the sample was colloidally stable and cryo-TEM analysis indicated that it was composed of a mixture of worms of different lengths-the shortest one resembling spheres-with an average diameter of $D_{\mathrm{n}}=14.7 \mathrm{~nm}$ (Figure 7A). The morphology was also studied by means of SAXS as illustrated on Figure 7B. The experiments at $20^{\circ} \mathrm{C}$ (at $1 \mathrm{wt} \%$ ), confirmed the worm-like morphology observed by cryo-TEM. Upon heating to $70{ }^{\circ} \mathrm{C}$ the 
scattering profile evolved towards aggregated fibers, with the appearance of structure factor displaying a broad characteristic peak, corresponding to a distance of around $21 \mathrm{~nm}$ $(d=2 \pi / q)$ between aggregated fibers. Interestingly, when the sample was cooled back to room temperature, this aggregation seems to be partially reversible, at the timescale of the experiment. Indeed, a worm-like form factor $\left(\mathrm{q}^{-1}\right)$ similar to the one obtained originally was measured, however with a reduced overall intensity, indicating less scattering light objects compared to the original sample.

(A)

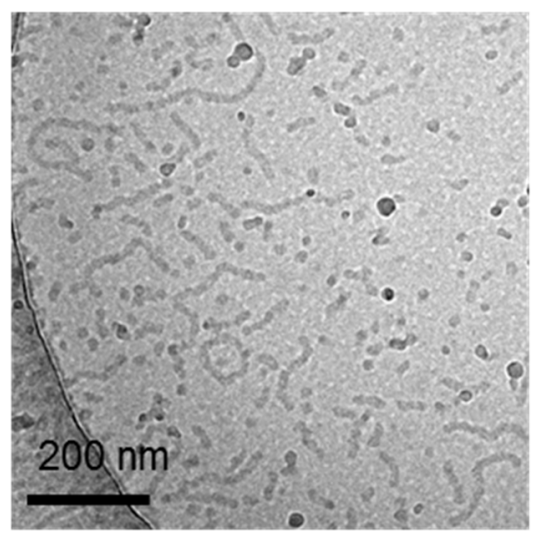

(B)

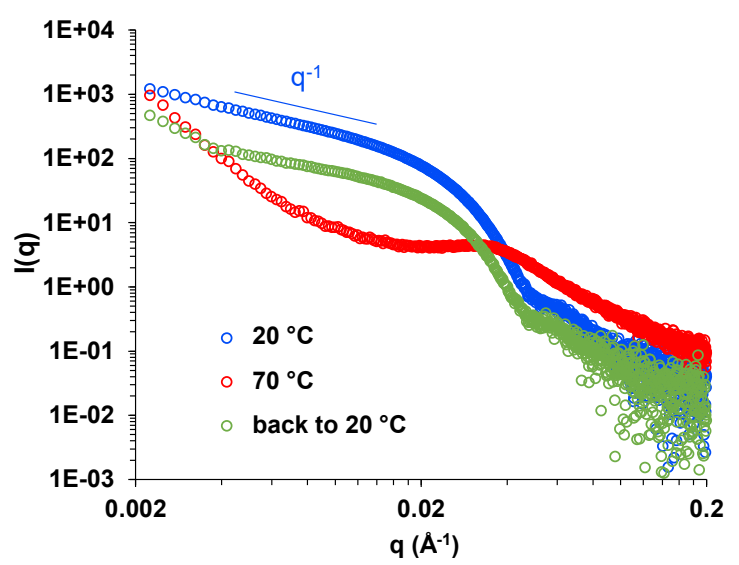

Figure 7. PDMAm 23 -b-PCMAm 93 (sample 3) aqueous dispersions: (A) Representative cryo-TEM image prepared at room temperature at $1 \mathrm{wt} \%$; (B) SAXS profile at $1 \mathrm{wt} \%$ at $20^{\circ} \mathrm{C}$ (in blue), $70{ }^{\circ} \mathrm{C}$ (in red) and back to $20^{\circ} \mathrm{C}$ (in green).

DLS analyses at $1 \mathrm{wt} \%$ were not reliable upon heating to $70{ }^{\circ} \mathrm{C}$ as the sample phase separated during the measurement, while at $0.1 \mathrm{wt} \%$ no phase separation was observed (Figure S10). Instead, Figure S10A showed a reversible increase in diameter when the sample was heated from 20 to $70{ }^{\circ} \mathrm{C}$, which is in agreement with the SAXS analyses. In more details, at $0.1 \mathrm{wt} \%$, we observed the presence of small sub-100 $\mathrm{nm}$ aggregates at $20{ }^{\circ} \mathrm{C}$, which evolved towards larger aggregates upon heating to $70{ }^{\circ} \mathrm{C}$. When the sample was further heated to $90{ }^{\circ} \mathrm{C}$ the scattering intensity dropped to a value close to water. This decrease might be explained by either (a) the molecular dissolution of the assemblies or (b) a macroscopic precipitation of the polymer toward the bottom of the unstirred cuvette (which was not observed but might be difficult to observe by the naked eye in view of the low sample concentration). At higher concentration, at $1 \mathrm{wt} \%$, heating the sample to $70{ }^{\circ} \mathrm{C}$ caused a destabilization of the system and the precipitation of the polymer visible at the bottom of the DLS cuvette. The remaining polymer formed micrometer-sized aggregates that precipitated over time. Rapid heating of the sample from RT to $90{ }^{\circ} \mathrm{C}$ led also to a very low scattering intensity and small objects below $10 \mathrm{~nm}$ were detected. Again, this could be attributed to either the molecular dissolution or macroscopic precipitation of the sample. Visually, we did not detect any deposit, and we can thus conclude that the polymer molecularly dissolved at $90^{\circ} \mathrm{C}$. Finally, at both sample concentrations ( 0.1 and $\left.1 \mathrm{wt} \%\right)$, the initial size of the small aggregates was recovered when the samples were cooled back to $20{ }^{\circ} \mathrm{C}$; the transition is thus reversible (Figure S10) as already indicated by turbidimetry. In view of theses combined analyses, the apparent LCST-type transition, might therefore be explained by the destabilization of the colloidal system [27]. At both concentrations, upon heating from 20 to $70{ }^{\circ} \mathrm{C}$, the initial aggregates form larger aggregates through a secondary aggregation mechanisms, which are nanometric and remain colloidally stable at $0.1 \mathrm{wt} \%$, but become micrometric and colloidally unstable at $1 \mathrm{wt} \%$. When the samples are further heated, the apparent UCST transition observed by turbidimetry above $\sim 90{ }^{\circ} \mathrm{C}$ should be attributed to the dissociation and solubilization of the polymer chains. 


\section{Discussion and Conclusions}

In summary, we demonstrated the possibility to synthesize in water-via RAFT-mediated PISA-block copolymer nanoassemblies with PCMAm as a hydrophobic block, using hydrophilic PDMAm-TTC macroRAFT agents. Overall, we demonstrated the formation of well-defined PDMAm- $b$-PCMAm diblock copolymers with good polymerization control. We have shown that a sufficient stabilizer/hydrophobic block ratio was crucial for the preparation of colloidally stable dispersions.

In Figure 8, we attempted to rationalize the influence of the respective block length, i.e., $D P_{\mathrm{n}}$, of the hydrophilic stabilizing block, PDMAm, and the PCMAm hydrophobic block, on the colloidal stability and morphologies obtained during the PISA process.

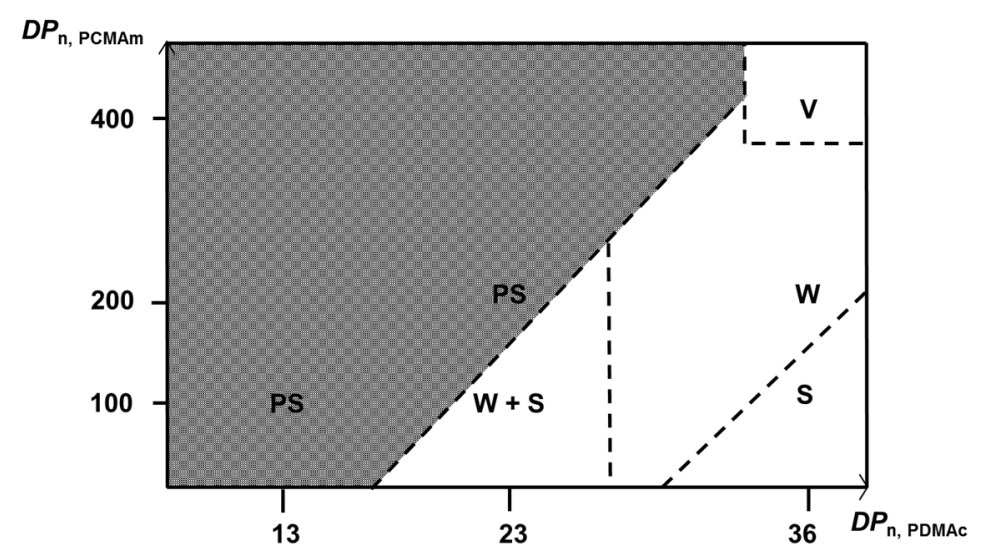

Figure 8. Supposed phase diagram for PDMAm- $b$-PCMAm diblock copolymers prepared at $10 \mathrm{wt} \%$ monomer concentration in water. PS = phase separation, $\mathrm{S}=$ spheres, $\mathrm{W}=$ worms, $\mathrm{V}=$ vesicles.

As indicated by the gray zone in the pseudo-phase diagram, short PDMAm blocks lead to unstable dispersions at the end of the polymerization, whereas large PDMAm block $\left(D P_{n}=36\right)$ enabled the synthesis of stable nano-objects, of which the morphology could be

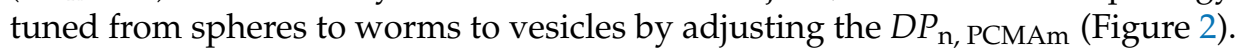

Even though short PCMAm blocks were shown to possess an UCST when studied as a homopolymer [11], most of the diblock copolymers studied here did not exhibit any typical UCST behavior. Only diblocks with a short PCMAm block $\left(D P_{n, P C M A m}<100\right)$ dissociated at low concentration upon heating. Yet for higher $D P_{n, P C M A m} \mathrm{~s}$, the diblock copolymer assemblies did not dissociate upon heating, nor displayed any morphological transition. At sufficiently high temperature, they rather exhibited a temperature-dependent secondary aggregation of primary particles, which explained the observed decrease in transmittance in the turbidimetry measurements.

We believe that our development of an aqueous synthesis pathway towards PCMAmbased copolymers will pave the way towards many other PCMAm-based responsive nanoobjects, notably thermoresponsive nanogels that will be highly valuable for biomedical applications.

Supplementary Materials: The following data are available online at https:/ / www.mdpi.com/ article/10.3390/polym13244424/s1. Scheme S1: Synthesis route for the PDMAm-TTC macroRAFT agents via RAFT-mediated solution polymerization in the presence of CTA-1; Table S1: Experimental conditions and results for the RAFT-mediated polymerization of DMAm in DMF at $70{ }^{\circ} \mathrm{C}$; Figure S1: ${ }^{1} \mathrm{H}-\mathrm{NMR}$ spectrum of M3 (Table S1) in $\mathrm{CDCl}_{3}$; Figure S2: SEC chromatograms in DMF $(+\mathrm{LiBr})$ of the macroRAFT agents with different $D P_{\mathrm{n}} \mathrm{s}$; Figure S3: Temperature-dependent size distribution determined by DLS at $0.1 \mathrm{wt} \%$ in water for Samples 5, 6 and 7 (PDMAm $36-b-$ PCMAm $_{\mathrm{x}}$ ); Figure S4: SAXS intensity (I) versus scattering vector $(\mathrm{q})$ for selected diblock PDMAm- $b$-PCMAm samples at $1 \mathrm{wt} \%$ in water at $25{ }^{\circ} \mathrm{C}$ (Samples 5, 6 and 7, Table 1); Figure S5: SAXS intensity (I) versus scattering vector (q) for PDMAm $_{36}-b$-PCMAm 186 (Sample 6) in water at (A) $1 \mathrm{wt} \%$; (B) $0.5 \mathrm{wt} \%$ and (C) $0.1 \mathrm{wt} \%$ in water at $25^{\circ} \mathrm{C}$ (or $20^{\circ} \mathrm{C}$ ) and $70{ }^{\circ} \mathrm{C}$; Figure S6: Selected cryo-TEM image of 
Sample 7 (PDMAm $36-b$-PCMAm 360 ) prepared at $70{ }^{\circ} \mathrm{C}$, showing the presence of other morphologies than vesicles. Sample concentration $=1 \mathrm{wt} \%$ in water. Figure S7: SAXS intensity (I) versus scattering vector (q) for PDMAm $36-b$-PCMAm 360 (Sample 7) in water at (A) $0.5 \mathrm{wt} \%$ and (B) $0.1 \mathrm{wt}^{\mathrm{O}} \%$ at $25{ }^{\circ} \mathrm{C}$ (dark blue), $70{ }^{\circ} \mathrm{C}$ (red) and back to $25^{\circ} \mathrm{C}$ (light blue). Thearrows designate $\mathrm{d}$, the reciprocal length corresponding to the inter-vesicle distance; Figure S8: Size distributions determined by DLS of (A) PDMAm 13 -b-PCMAm $\sim 90$ (Sample 1), (B) PDMAm 23 -b-PCMAm 90 (Sample 3) and (C) PDMAm $_{36}-b$-PCMAm 91 (Sample 5) dispersions prepared at $1 \mathrm{wt} \%$ in water at various temperatures; Figure S9: SAXS intensity (I) versus scattering vector (q) for PDMAm $_{36}-b$-PCMAm 91 (Sample 5) in water at $0.1 \mathrm{wt} \%$ at $25^{\circ} \mathrm{C}$ (dark blue), $70^{\circ} \mathrm{C}$ (red) and back to $25^{\circ} \mathrm{C}$ (light blue); Figure S10: Size distribution of Sample 3 (PDMAm $23-b$-PCMAm 93 ) at (A) $0.1 \mathrm{wt} \%$ and (B) $1 \mathrm{wt} \%$ in water determined by DLS at different temperatures (solid lines, first heating, dashed lines first cooling). At $90{ }^{\circ} \mathrm{C}$ a very low scattering intensity was detected $(\mathrm{kcps}=6$ and 50 , respectively for $0.1 \mathrm{wt} \%$ and $1 \mathrm{wt} \%)$.

Author Contributions: Conceptualization, F.S. and J.R.; formal analysis, F.C., C.G., N.A.; investigation, N.A., C.V., J.-M.G. and F.C.; visualization, N.A., F.C.; writing-original draft preparation, J.R.; writing-review and editing, J.R., F.S., F.C. and C.G.; supervision, J.R., F.S. and F.C. All authors have read and agreed to the published version of the manuscript.

Funding: This research was funded by the Sorbonne Universite Doctoral School ED397 and the Synchrotron Soleil (grant $N^{\circ}$ 20201382).

Institutional Review Board Statement: Not applicable.

Informed Consent Statement: Not applicable.

Data Availability Statement: Data sharing not applicable.

Acknowledgments: The authors gratefully acknowledge SOLEIL for provision of synchrotron radiation facilities through the project 20201382 and they would like to thank T. Bizien for assistance in using the SWING beamline.

Conflicts of Interest: The authors declare no conflict of interest.

\section{References}

1. Zhao, C.; Ma, Z.; Zhu, X.X. Rational Design of Thermoresponsive Polymers in Aqueous Solutions: A Thermodynamics Map. Prog. Polym. Sci. 2019, 90, 269-291. [CrossRef]

2. Kim, Y.-J.; Matsunaga, Y.T. Thermo-Responsive Polymers and Their Application as Smart Biomaterials. J. Mater. Chem. B 2017, 5, 4307-4321. [CrossRef]

3. Bansal, K.K.; Upadhyay, P.K.; Saraogi, G.K.; Rosling, A.; Rosenholm, J.M. Advances in Thermo-Responsive Polymers Exhibiting Upper Critical Solution Temperature (UCST). Express Polym. Lett. 2019, 13, 974-992. [CrossRef]

4. Roy, D.; Brooks, W.L.A.; Sumerlin, B.S. New Directions in Thermoresponsive Polymers. Chem. Soc. Rev. 2013, 42, 7214-7243. [CrossRef] [PubMed]

5. Seuring, J.; Agarwal, S. Polymers with Upper Critical Solution Temperature in Aqueous Solution. Macromol. Rapid Commun. 2012, 33, 1898-1920. [CrossRef] [PubMed]

6. Seuring, J.; Agarwal, S. Polymers with Upper Critical Solution Temperature in Aqueous Solution: Unexpected Properties from Known Building Blocks. ACS Macro Lett. 2013, 2, 597-600. [CrossRef]

7. Seuring, J.; Agarwal, S. First Example of a Universal and Cost-Effective Approach: Polymers with Tunable Upper Critical Solution Temperature in Water and Electrolyte Solution. Macromolecules 2012, 45, 3910-3918. [CrossRef]

8. Seuring, J.; Agarwal, S. Non-Ionic Homo- and Copolymers with H-Donor and H-Acceptor Units with an UCST in Water. Macromol. Chem. Phys. 2010, 211, 2109-2117. [CrossRef]

9. Käfer, F.; Pretscher, M.; Agarwal, S. Tuning the Phase Transition from UCST-Type to LCST-Type by Composition Variation of Polymethacrylamide Polymers. Macromol. Rapid Commun. 2018, 39, 1800640. [CrossRef]

10. Akiyama, Y. Synthesis of Temperature-Responsive Polymers Containing Piperidine Carboxamide and $N, N$-diethylcarbamoly Piperidine Moiety via RAFT Polymerization. Macromol. Rapid Commun. 2021, 42, 2100208. [CrossRef]

11. Audureau, N.; Veith, C.; Coumes, F.; Nguyen, T.P.T.; Rieger, J.; Stoffelbach, F. RAFT-Polymerized N-CyanomethylacrylamideBased (Co)Polymers Exhibiting Tunable UCST Behavior in Water. Macromol. Rapid Commun. 2021, 42, 2100556. [CrossRef] [PubMed]

12. Fu, W.; Zhao, B. Thermoreversible Physically Crosslinked Hydrogels from UCST-Type Thermosensitive ABA Linear Triblock Copolymers. Polym. Chem. 2016, 7, 6980-6991. [CrossRef]

13. Augé, A.; Fortin, D.; Tong, X.; Zhao, Y. Nanogel-like UCST Triblock Copolymer Micelles Showing Large Volume Expansion before Abrupt Dissolution. Polym. Chem. 2018, 9, 4660-4673. [CrossRef] 
14. Wu, L.; Zong, L.; Ni, H.; Liu, X.; Wen, W.; Feng, L.; Cao, J.; Qi, X.; Ge, Y.; Shen, S. Magnetic Thermosensitive Micelles with Upper Critical Solution Temperature for NIR Triggered Drug Release. Biomater. Sci. 2019, 7, 2134-2143. [CrossRef]

15. Chen, L.; Yang, T.; Niu, Y.; Mu, X.; Gong, Y.; Feng, Y.; de Rooij, N.F.; Wang, Y.; Li, H.; Zhou, G. Building a Smart Surface with Converse Temperature-Dependent Wettability Based on Poly(Acrylamide-co-Acrylonitrile). Chem. Commun. 2020, 56, 2837-2840. [CrossRef]

16. Zhou, C.; Chen, Y.; Huang, M.; Ling, Y.; Yang, L.; Zhao, G.; Chen, J. A PH and UCST Thermo-Responsive Tri-Block Copolymer (PAA-b-PDMA-b-P(AM-Co-AN)) with Micellization and Gelatinization in Aqueous Media for Drug Release. New J. Chem. 2020, 44, 14551-14559. [CrossRef]

17. Lertturongchai, P.; Ibrahim, M.I.A.; Durand, A.; Sunintaboon, P.; Ferji, K. Synthesis of Thermoresponsive Copolymers with Tunable UCST-Type Phase Transition Using Aqueous Photo-RAFT Polymerization. Macromol. Rapid Commun. 2020, 41, 2000058. [CrossRef]

18. Audureau, N.; Coumes, F.; Guigner, J.-M.; Nguyen, T.P.T.; Ménager, C.; Stoffelbach, F.; Rieger, J. Thermoresponsive Properties of Poly(Acrylamide- co -Acrylonitrile)-Based Diblock Copolymers Synthesized (by PISA) in Water. Polym. Chem. 2020, 11, 5998-6008. [CrossRef]

19. Chapiro, A.; Perec-Spritzer, L. Influence des solvants sur la copolymérisation de l'acrylamide avec l'acrylonitrile. Eur. Polym. J. 1975, 11, 59-69. [CrossRef]

20. FUJIFILM Wako Pure Chemical Corporation. 2,2'-Azobis[2-(2-Imidazolin-2-Yl)Propane]Dihydrochloride (VA-044). Available online: https: / / specchem-wako-jp.fujifilm.com/en/waterazo/VA-044.htm\# (accessed on 17 June 2021).

21. Grazon, C.; Rieger, J.; Sanson, N.; Charleux, B. Study of Poly(N,N-Diethylacrylamide) Nanogel Formation by Aqueous Dispersion Polymerization of N,N-Diethylacrylamide in the Presence of Poly(Ethylene Oxide)-b-Poly(N,N-Dimethylacrylamide) Amphiphilic Macromolecular RAFT Agents. Soft Matter 2011, 7, 3482-3490. [CrossRef]

22. Rieger, J.; Osterwinter, G.; Bui, C.; Stoffelbach, F.; Charleux, B. Surfactant-Free Controlled/Living Radical Emulsion (Co)Polymerization of $n$-Butyl Acrylate and Methyl Methacrylate via RAFT Using Amphiphilic Poly(Ethylene Oxide)-Based Trithiocarbonate Chain Transfer Agents. Macromolecules 2009, 42, 5518-5525. [CrossRef]

23. Zhang, W.; Charleux, B.; Cassagnau, P. Viscoelastic Properties of Water Suspensions of Polymer Nanofibers Synthesized via RAFT-Mediated Emulsion Polymerization. Macromolecules 2012, 45, 5273-5280. [CrossRef]

24. Magnet, S.; Inoubli, R.; Couvreur, L.; Charleux, B.; Brusseau, S. Filamentous Polymer Particles and Use Thereof as Rheology Modifieres. Patent WO 2012085473, 28 June 2012.

25. Lovett, J.R.; Derry, M.J.; Yang, P.; Hatton, F.L.; Warren, N.J.; Fowler, P.W.; Armes, S.P. Can Percolation Theory Explain the Gelation Behavior of Diblock Copolymer Worms? Chem. Sci. 2018, 9, 7138-7144. [CrossRef] [PubMed]

26. Maji, T.; Banerjee, S.; Biswas, Y.; Mandal, T.K. Dual-Stimuli-Responsive L -Serine-Based Zwitterionic UCST-Type Polymer with Tunable Thermosensitivity. Macromolecules 2015, 48, 4957-4966. [CrossRef]

27. Mellot, G.; Guigner, J.-M.; Jestin, J.; Bouteiller, L.; Stoffelbach, F.; Rieger, J. Unexpected Thermo-Responsiveness of Bisurea-Functionalized Hydrophilic Polymers in Water. J. Colloid Interface Sci. 2021, 581, 874-883. [CrossRef] [PubMed] 